\title{
The Nutrition Transition's Effect in Lebanon: A Qualitative Study Exploring Adolescents' Perspectives in Both Urban and Rural Areas
}

\author{
Miriam Bou Kheir ${ }^{1}$ and Stephen Fallows \\ University of Chester, United Kingdom \\ Lynne Kennedy \\ Zayed University, United Arab Emirates
}

\begin{abstract}
Adolescent obesity is a major public health concern, increasingly affecting low and middleincome countries (LMICs) undergoing the nutrition transition. In developed countries, governments had the time to adjust to this rise in the consequent non-communicable diseases (NCDs), whereas the developing world is facing a triple burden of nutrition-related disease simultaneously. However, amidst the nutrition transition, drivers to obesity may differ within the same country especially between the urban and rural areas, depending on the context and environmental factors. In order to unravel how the nutrition transition process unfolds in both urban and rural areas, an exploration of the factors affecting adolescents' lifestyle and eating behaviors, in the current context was deemed appropriate. Almost similar behaviors were perceived between the urban and rural area, showcasing the impact of the nutrition transition in both areas although different underlying factors were stated. The factors identified in this study were grouped and discussed based on the socio-ecological model (SEM) highlighting the importance of the social and environmental influences on adolescents' eating behaviors. Given the findings of this study regarding the dramatic changes affecting both urban and rural areas regarding the number of meals consumed away from home, the increase in fast-food consumption and the increase in sedentary lifestyles, new challenges in relation to adolescent obesity prevention in LMICs are created. The creation of supportive local environments, in both urban and rural areas, represents an important avenue where eating behaviors concerns, and thus adolescents' obesity can be addressed.
\end{abstract}

KEYWORDS: Adolescence, Low-Middle Income Countries, Obesity, Policies, Public Health.

Obesity prevalence has been increasing worldwide and nearly tripled between 1975 and 2016; the global prevalence of obesity in the last 30 years has been on the rise across all age groups (World Health Organization [WHO], 2018). The increase in obesity prevalence and changes to body composition might be the reflection of the changes due to the nutrition and demographic transition (Popkin, 2015; WHO, 2017). Although the rise in obesity prevalence has been plateauing across high-income countries (Kleinert \& Horton, 2015), it is though still increasing rapidly in low- and middle-income countries (Lobstein et al., 2015). Roth et al. (2012) noted that the epidemic of obesity has become pandemic reaching a high proportion of the population and spreading over a wide geographic area. Pertaining to this, research asserted that all countries in the world are affected by the scale of obesity (Swinburn et al., 2019).

\footnotetext{
${ }^{1}$ Correspondent Author E-Mail: m.boukheir@chester.ac.uk
} 
According to the Global Burden of Disease Study 2010, the Eastern Mediterranean Region (EMR) is facing an increased burden of non-communicable diseases with the obesity epidemic reaching alarming levels especially amongst children and adolescents (Abdul Rahim et al., 2014). The EMR includes countries of the Middle East and the Gulf region including Lebanon.

On the most basic level, obesity is a disease characterized by the increased body fat due to a daily energy imbalance (Gortmaker et al., 2011; Murray \& Battista, 2009). Yet, the drivers behind obesity seem to include physiological, behavioral, and environmental factors exposing the person to an increased obesity susceptibility (WHO, 2016b). For that, obesity has been seen as a multi-factorial and complex phenomenon (Butland \& Jebb, 2007). The current study focused on investigating the experience and perceptions of adolescents regarding their eating behaviors in both urban and rural areas of Lebanon undergoing the nutrition transition.

\section{Background Information}

There is a crucial need to combat the epidemic of obesity amongst adolescents in the EMR especially as variances in the rates have been shown which might be due to different cultural practices along with the pace of rapid development (Musaiger, 2011). More particularly, an increasing trend of obesity amongst school-aged children in Lebanon and the Kingdom of Saudi Arabia is of concern (Nasreddine et al., 2017). It appears that governmental response to the increase of NCDs is still weak in the EMR and differs between countries with an overall poor implementation of public policies (Abdul Rahim, 2014).

Lebanon is a small upper middle-income eastern Mediterranean country situated on the Mediterranean basin that is currently facing rapid development and modernization along with other countries in the EMR (Bahn \& Abebe 2017; Nasreddine et al., 2014). Lebanon is divided into six "governorates" representing the administrative regions (Nasreddine et al., 2014). Lebanon's population has been estimated at 6.86million in 2019 (United Nations Population Division, 2019). Beirut's governorate is purely urban home to around 400000 Lebanese residents; all other governorates combine both urban and rural regions (Bahn \& Abebe, 2017; Nasreddine et al., 2014). Adjacent to Beirut, is the Mount Lebanon governorate which combines both urban and rural areas and home to around 1.5 million Lebanese residents (Bahn \& Abebe, 2017). In addition, the largest rural populations have been reported to reside in Mount Lebanon and Bekaa governorates (Bahn \& Abebe, 2017). In the Middle East region, Lebanon represents a very complex and diverse model with the main two religions being Christian and Muslim which are further divided into seventeen different sects such as Catholic, Orthodox, Sunni and Druze.

The association of increased adiposity with metabolic syndrome and the high prevalence (24\%) of metabolic syndrome amongst obese adolescents in Lebanon, (exceeding rates reported in some developed countries such as Italy (16.5\%)), could be related to the nutrition transition and the shift in dietary patterns (Caranti et al., 2008; Nasreddine et al., 2012). More particularly, adolescents in Lebanon appear to have a higher level of sedentary behavior compared with younger children (Nasreddine et al., 2014). However, recent national epidemiological studies in Lebanon regarding the nutrition transition, adolescents' obesity and NCDs' prevalence are lacking; thereby, researchers rely solely on targeted research based on specific samples (Nasreddine et al., 2012). A systematic review by Naja et al. (2017) exploring the studies on dietary patterns in Lebanon, indicated that very few studies included data collected from children and adolescents with most studies focusing on the examination of nutrition in isolation excluding other environmental factors (Naja et al., 2017).

The recognition of the public health principle in promoting health of the population through an integrated approach targeting the social determinants of health and lifestyle choices has led towards the adoption of the health-promoting models of health (Lee et al., 2007; Oliver 
\& Peersman, 2001). Therefore, the importance of this study is the use of a qualitative research design that is not analyzed mathematically but rather that explores several social factors and identifies complex elements' interactions (Creswell, 2007). Regarding childhood obesity prevention research, although many causes and factors are known, the qualitative approach is deemed essential to fill in the gap concerning barriers and facilitators to obesity and changes in behaviors of affected people (Swinburn et al., 2011). A qualitative approach is warranted to explore complex and deeper insights of adolescent obesity and the barriers faced in its prevention. The study of adolescents' perspectives and attitudes is relevant in this domain as a person's attitude is related to choosing a certain behavior.

\section{Literature Review}

During this vulnerable period, eating patterns acquired in adolescence tend to remain for the entire life (Montaño et al., 2015). Not only do dietary patterns tend to alter during this period as autonomy increases but a decrease in physical activity has been observed as well (Hills et al., 2011). The combination of dietary changes and decreased physical activity during this life stage along with the nutrition transition makes adolescents more prone to NCDs (Spear, 2002).

In the prevention of obesity, multilevel approaches incorporating changes to the individual's environmental factors, currently perceived to be the root causes of obesity, have been evidenced to be highly appropriate (De Mattia \& Denney, 2008; Panter et al., 2018). The prevention of obesity through lifestyle modifications at national level has been endorsed through the implementation of national nutrition and physical activity guidelines, changes to the school curriculum, the provision of free school lunches and an increase in health promotion in the worksite (Panter et al., 2018; WHO, 1986, 2000). Previous failures in obesity interventions are the result of the individualist paradigm aiming solely to influence the individual's behavior without taking into account the environmental determinants (Salas, 2015).

Urbanization and globalization are key factors in the nutrition transition and directly affecting the individual's eating behaviors through increased diversity of food available in urban areas, supermarket expansions, and consumers' lack of awareness of the processes by which their food is produced (Tull, 2018). Although globalization had a positive effect on the economic process, some epidemiological studies have identified a negative aspect on individuals' health and nutritional status which is built on the modernization theory (Fox et al., 2019; Omran, 1971). Two theories have been used to explain the increase in obesity in LMICs: first, the theory of modernization that correlates the increase in gross domestic product (GDP) per capita with a linear increase in body mass index (BMI) while the second theory, the dependency theory correlates obesity to the integration of global economy and Western culture (Fox et al., 2019). While the first theory encourages the adoption or desire to adopt new innovations found in other cultures, particularly higher income countries, the second theory relies on the countries' international trade and transnational food corporations (Fox et al., 2019). The growing spread of the obesogenic environment has been acknowledged to play a major role in the prevalence of obesity (Swinburn et al., 1999; Weihrauch-Blüher et al., 2018). The obesogenic environment provides increased opportunities for fast food consumption, increased intake away from home and restricted opportunities for physical activity (Holsten, 2009; Lopez et al., 2017; Mackenbach et al., 2014).

The nutrition transition is deeply related to the process of globalization which facilitated the diffusion of obesogenic products, such as highly processed and manufactured foods, take away foods and sugar-sweetened beverages, even to LMICs (De Vogli et al., 2014; Lopez et al., 2017; Oberlander et al., 2017). The emerging unhealthy dietary behaviors related to cheap available 'modern' ultra-processed foods and increase in sedentary lifestyle across all age 
groups have led directly to an increase in diet-related non-communicable diseases (Rockefeller Foundation, 2013; WHO, 2016a). For that, the globalization process together with income increases and cheapening of processed foods, increased the epidemic of obesity whilst making healthy food supplies such as fruits and vegetables only accessible to high income populations due to their higher costs (Black, 2016; Siegel, 2019).

Another factor of the obesogenic environment is the increased availability of fast-food restaurants and increased food intake away from home. Not only are fast foods higher in calories and fat and served in large portion sizes but it was suggested that opting for a healthy main dish in these restaurants based on the readily available nutritional information is not easily possible (Fraser et al., 2011; Stewart et al., 2006; Wang et al., 2019). In addition to the environmental obesogenic factors, multiple key elements, such as social factors, play a role in the increased epidemic of adolescent obesity (Weihrauch-Blüher et al., 2018). Yet, healthier environments are very important in creating healthier behaviors; studies have associated a positive effect on health behaviors and weight status with accessibility of environmental factors such as parks and residential neighborhoods (Lange et al., 2011; Weihrauch-Blüher et al., 2018).

\section{Theoretical Framework}

The theoretical framework of this study is grounded in Bronfenbrenner's (1992) bioecological model, framing adolescents' obesity in the Socio-Ecological Model (SEM) with multiple levels affecting the individual's eating behaviors including the individual, social, organizational, environmental and policy level (Butland \& Jebb, 2007; Finegood et al., 2010; Ulijaszek, 2015). Using an ecological model framework has been argued to allow the identification of multiple determinants of population health by determining specific individual and environmental changes at each level of intervention (McLeroy et al., 1988; Simons-Morton et al., 1988).

In addition to the effect of the determinants of health, this study considers the importance of social origins explained by Bourdieu (1986). Food consumption patterns are deemed to be key elements in the family's identity, children's socialization, and class identity (O'Connell, 2010). From a cultural perspective, higher economic groups tend to adopt healthier eating behaviors to differentiate themselves from low socioeconomic groups whilst low socioeconomic groups tend to opt for cheaper unhealthy foods to expose their "freedom from convention" (Kamphuis et al., 2015; Pampel et al., 2010). The child's eating behavior defined as "nutritional habitus" is shaped by the mothers' feeding practices- in countries where the male-breadwinner model is still prominent- which are influenced by the economic and cultural background of the household (Oncini \& Guetto, 2017). Bourdieu's (1986) theory on food taste may be the first sociological study on food stratification; explaining the influence of cultural and economic capital on the individual food preferences. Similar eating behaviors are perceived within the same social class and generation which could be explained by the need of socialization and cultural belonging (Kamphuis et al., 2015). In fact, some studies have showed a positive association between the educational level and cultural participation with better health (Pampel, 2011; Pinxten \& Lievens, 2014). Bourdieu's theory also takes into consideration the reproduction of behavioral patterns over time and generations which is influenced by parental cultural capital (Bourdieu, 1986; Oncini \& Guetto, 2017). However, cultural capital is an unconscious form of custom and belief reproduction, giving a sense of making the right choice (Bourdieu, 2010; Kamphuis et al., 2015). Bourdieu (1998) explained:

When habitus encounters a social world of which it is the product, it finds itself 'as a fish in water', it does not feel the weight of the water and takes the world about itself for granted. 


\section{Research Design}

Qualitative research methods examine people's actions and words to develop "thick descriptions of a given social world analyzed for cultural patterns and themes" (Warren, 2002). Barbour and Kitzinger (1999), explained that in the absence of information on the topic under examination the use of focus group interviews is specifically valuable as they give insight about what individuals think and why they think in this certain way. The use of focus groups, a recognized research method, has been successfully employed with adolescents in previous health research (Bagnoli \& Clark, 2010; Demant \& Järvinen, 2006; Fielden et al., 2011; Moffat et al., 2009; Morgan et al., 2002). Focus groups were thought to give more insight on the research subject as participants tend to exchange ideas in a more naturalistic, non-threatening, friendly environment (Acocella, 2012). The focus groups discussions and field notes allow a comprehensive understanding of the phenomenon. Additionally, field notes were collected between questions during the interviews (Creswell \& Poth, 2018). The data were transcribed, coded, and developed into themes to further reinforce validity and reliability.

Finally, the researcher in this study had both the roles of the researcher and the translator. The researcher being embedded culturally within the research setting as she is from the same country, gave her an added value on what to preserve during the translation keeping in mind the aim to preserve the authenticity and transparency of the translated text. Hence, the use of the translation process called naturalization was used (Molina \& Albir, 2004). The translation process was only used for the in-text citations and quotations and for some of the interviews to serve as a "proof". The researcher being a doctoral candidate in the UK gave her insight of the cultural background of the audience. In addition, the researcher being the translator, in text-citations were sometimes translated verbatim although taking the risk of not making sense; however, this process is called "borrowing" and in turn increases the authenticity of the data (Molina \& Albir, 2004). To ensure the accuracy of the translation, some of the selected in-text quotations were back translated (translated from English back to the original language) by a colleague who was both fluent in English and the dialect in Lebanon without having access to the original transcription. Using the back-translation technique should assure the accuracy of the translation, however, like other methods, it represents flaws (Oxley et al., 2017).

\section{Participant's Background}

A purposive two-segment of 78 adolescents aged from 16 to 18 in Grades 10, 11 and 12 were recruited from both urban and rural schools to participate in the focus groups discussion. Adolescents aged between 16 and 18 years, who consented to participate in the research and who were given parental signed consent were included. The sampling technique used in the current research was purposive sampling for the schools, however participants were randomly selected within each school. This ensured that the researcher was not biased in selection and gave assurance that the sampling technique was representative of the larger group (Bouma \& Atkinson, 1995). The selection of participants through a two-segment sampling design was chosen as the population is naturally segmented into two distinct structures being the urban and the rural areas. This sampling design is a non-random technique that does not rely on an established number of participants; however, Krueger and Casey (2009) suggested that saturation occurs between four and six focus groups. Most of the Lebanese population live in urban areas $(81 \%)$ while the rural population is in decline, therefore, the urban school facilitated seven focus groups while the rural one only facilitated four focus groups. A total of eleven focus groups were conducted in the first phase. All focus groups were segmented based on their age group to increase the homogeneity of the sample. 


\section{Ethical Considerations}

Ethical approval was obtained from the Faculty of Medicine, Dentistry and Life Sciences Research Ethics Committee at the University of Chester (\#1376/17/MBK/CSN) in order to carry out the research. Additionally, consent was taken from the two schools' director in order to carry the research within their premises. All participants and their parents signed a consent letter indicating their willingness to participate and researcher assured anonymity to all participants by the use pseudonyms to ensure confidentiality (Creswell, 2014). Internal validity was established through triangulation involving multiple methods, multiple sources, and member checking (Lincoln \& Guba, 1985), to reduce researcher bias, and increase reflexivity.

\section{Data Collection Process}

The data collection process included in-depth, semi structured focus groups discussions, observation and field notes taken during the interviews. These data allowed the researcher to compose a rich narrative description of the findings. Focus groups took place in an empty classroom provided by the school principal; chairs were arranged in a circle and each participant filled their name on an empty name tag. All participants' names and the schools they attended were altered for confidentiality. Interviews were semi-structured with open-ended and subsequent follow-up and probing questions. The interviews ranged from 30 to 70 minutes, were audio recorded, and subsequently transcribed verbatim. The first two focus-group interviews in the urban school were initially considered as pilot interviews and aimed to determine the relevance and suitability of the questions used in these focus-group discussions. Few changes in the questions' order were made to increase the adolescents' interest in the studied subject and to encourage participants to speak. However, the content did not change and thus the data were used in the final analysis. Field notes allowed a deeper understanding of participants' perceptions, increasing trustworthiness and credibility of the findings.

An emergent, unexpected, problem in these focus group discussions was the language adopted by the adolescents. The language expressed in a culture has been directly related to the human experience, thus, making the processes of data collection and analysis more complicated in cross- cultural studies (Oxley et al., 2017). As focus groups discussion should have the aspect of a naturalistic group discussion and mimic their everyday conversation, participants often continued the conversation, and felt most at ease, while talking simultaneously in three languages. The focus groups' discussions were held in mix of all three languages. Considering the researcher is familiar with both the culture and the code-switching dialogue - knowing that the researcher is part of this culture and uses this dialogue fluently - there was no necessity for a translator, which might have impacted the dynamics of the interview (Elderkin-Thompson et al., 2001).

\section{Data Analysis}

The focus groups discussions were, recorded, transcribed verbatim and then distributed to a member that is familiar with all three languages for checking and confirmation. Transcription of the data has been done verbatim in the same language used for French and English. Romanization of Arabic relies primarily on phonemes ${ }^{2}$-to-graphemes ${ }^{3}$ mapping which makes it closer to being a transcription rather than a transliteration (Al-Badrashiny et al., 2014). However, Arabic phonemes with no Latin graphemes equivalent are sometimes rendered in numerals that look similar to the Arabic script grapheme (See Table1).

\footnotetext{
2 Phonemes are the sounds we hear in words.

${ }^{3}$ Graphemes are the shapes that represent the sounds.
} 
Table 1

Example of Arabic Phonemes Rendered in Numerical Grapheme

ARABIC PHONEMES NUMERAL GRAPHEMES

$\begin{array}{ll}\langle\varsigma\rangle & \langle 2\rangle \\ \langle\varepsilon\rangle & \langle 3\rangle \\ \langle\tau\rangle & \langle 7\rangle\end{array}$

All focus groups discussions were transcribed verbatim in the same language used into Microsoft Word documents and analyzed in all three languages. The analysis of the data has been argued to be more accurate when the researcher uses their technical first language rather than the presentation language (Oxley et al., 2017). Through an inductive thematic approach, the data was analyzed manually, read many times so the researcher could familiarize herself with the depth of the data and descriptively explain the patterns, initial codes and themes that emerged using the six steps process described by Braun and Clark, (2019). These initial codes led to the formation of five themes, that were eventually reviewed to ensure their validity. Direct quotations from the data were incorporated into the thick, rich descriptions of the perceptions and experiences of the adolescents (Creswell \& Poth, 2018). Thick rich description improved the reliability and transferability of the research as it provided a deeper insight into the phenomenon, setting, and other processes of this study.

\section{Themes}

The purpose of this study was to answer the research question which focuses on the experiences and perceptions of Lebanese adolescents of their eating behaviors and surrounding environment effect within the nutrition transition. The findings of the thematic analysis of the qualitative data centered on the various determinants of health in affecting adolescents' eating behaviors in Lebanon. Consistent with the literature on the nutrition transition characteristics, a shift from the traditional diet towards a Westernized diet was evidenced in these current discussions.

\section{Theme One: Weekdays Versus Weekends}

Majority of the adolescents in both urban and rural areas commented that the common food choices available during weekdays are traditional Lebanese stews. The home environment was perceived by the majority of adolescents, in both urban and rural areas, as an opportunity for healthy eating and behaviors, not from an individual choice but by their parental imposed food patterns and behaviors. It appeared that adolescents living in the urban area had less freedom and ability to go out during the week, after school-time, as they were headed directly towards their home. Some adolescents in the urban area emphasized as well on their parents' strict roles and the obligation to eat the prepared meal. Conversely, a higher number of participants, recruited in the rural area, mentioned the ability to reject a certain stew on a certain day. It seemed that adolescents living in the rural area were considered by their parents and themselves as young mature adults that have the freedom to reject and make their own decisions.

Most of the participants, in both urban and rural areas, emphasized on the difference between the Lebanese cuisine eaten during weekdays and the Lebanese Mezze eaten on Sundays with a clear preference towards Lebanese Mezze even some adolescents labelled it as "the Lebanese fast food" explaining: 
It depends on the food, like for example, taouk there is no one that doesn't' like it; everything that's chicken, meat there is no one that hates these but when we look at Lebanese stews like spinach and similar stews definitely there's a lot of people that wouldn't like them, like stuffed cabbage rolls and these like okay they're tasty but it depends. There is a specific thing about umm Lebanese traditions when it comes to food like it doesn't end. When you go to a traditional Lebanese meal it doesn't end there's something and there's something else and umm there is no way to control how much you're eating, you get very unconscious about what you eat and how much you eat(Urban, boy).

Additionally, in both rural and urban areas, adolescents' clear rejection for the availability of Lebanese stews on Sundays was obvious. Lebanese Mezze was described by adolescents as an enhancer for the feeling of conviviality as it is made of different little platters which would be shared between the entire family members; however, they did express the fact that the Lebanese Mezze is occasional, and it should stay that way.

According to most of the adolescents, Fridays and Saturdays are considered to be a reward of all the week's efforts in school. The majority of adolescents in both urban and rural areas clearly showed a preference for eating out with friends, this might be expressed in terms of demonstrating the feeling of independence, a sense of defiance and autonomy. Some adolescents expressed the feeling of defiance in choosing the foods that are mostly forbidden by their parents. The feeling of autonomy and defiance as well as the feeling of challenging boundaries and 'rules' implemented by parents during childhood, especially in presence of their peers was felt to be part of the creation of their social identity. This was agreed by adolescents living in the rural area too, by explaining the obligation of eating Western fast foods;

\begin{abstract}
Like for example imagine if I were to go to an 'open wings event' at a Western restaurant with my mother! She would jump over and be like "stop eating, slow down that's enough and she would just take the plate away". Like she's right, wings aren't that good but whatever (Rural, boy).
\end{abstract}

\title{
Theme 2: Western Food: A Proof of Freedom
}

The majority of adolescents agreed that the most important factor in choosing a Western type of restaurant over a Lebanese restaurant is boredom with Lebanese food. It appeared that majority of adolescents seemed to agree that the Lebanese traditional food was not innovative anymore nor special. Participants appeared to agree that the food eaten in Western restaurants was perceived as novel compared to the food they eat at home "it's something novel for us". A lot of participants have described adolescence as a period with increased freedom; the freedom of choices, the freedom to go out, to get food delivered and to make statements. Most of the adolescents expressed an unconscious feeling of choosing what is forbidden. There were also statements pertaining to wanting to eat fast food outside of home for the fact that restaurant foods should be different than the food eaten at home. This might be as well due to the nature of adolescents, wanting to challenge the rules put on by their parents. An increase in adolescents' rebellion during weekdays was perceived in the rural area.

For that, of course when we go out when we want to hang out with our friends for sure we don't go to a Lebanese restaurant because enough, we want to eat something different than Lebanese food (Urban, boy). 
Food consumption has been linked by many of the participants to the feeling of happiness and joy regardless of whether they are or aren't following healthy eating behaviors. A statement suggested as well that this reward system could be a common social norm amongst adolescents stating:

\begin{abstract}
Most of the time adolescents consider the time with their friends as a cheat day because 6 out of 7 days a week we eat something that is healthy and only 1 day at the end we change for a cheat meal so most of the time when we go out it's going to be a cheat day, it's a designated day (Urban, boy).
\end{abstract}

In accordance with the nutrition transition, it appeared that the majority of adolescents were primarily eating for 'pleasure' purposes rather than for the necessity of food. However, few adolescents were not driven by hedonistic attitudes when related to food choices. For instance, most of the adolescents living in the urban area expressed the need for a variety of food choices during the week as they would not stand Lebanese stews every single day; this was also apparent in the rural area amongst adolescents stating that they require their mothers to cook some kind of foods that are not traditional Lebanese stews. Few adolescent boys in the rural area expressed the occasional availability of home-made Western food such as burger and pizza.

The increased availability of home-made Western type foods in the rural area was controversial; although a majority of adolescents living in the rural area stated their parents' preference towards traditional Lebanese stews; yet it appeared that some Western foods were also available at their home. This might be due to the fact that parents might be providing some Western food at home to decrease adolescents' consumption of Western foods outside of their home. Yet, majority of adolescents, especially in the rural area, confirmed that their grandparents were still exclusively adhering to the traditional Lebanese cuisine. Perception of Lebanese traditional cuisine as healthy behavior has been used by the majority of adolescents to explain their grandparents' food behaviors; however, this was not perceived amongst all participants especially in the urban area; one adolescent emphasized that even her grandmother does make varieties of cuisines.

On the other hand, some of the participants, and specially, boys have mentioned the idea of a threat to the Lebanese cuisine, stating that many parents do not know how to cook some of the traditional cuisine. In turn, they described that the new generation will not have the required skills to cook these traditional Lebanese cuisines.

This was particularly stressed by some rural boys stating that a lot of old traditional Lebanese stews are really hard to learn and even nowadays are less likely to be eaten or cooked whether at home or outside. There were some evident cultural inherited norms that women should be the one responsible for cooking at home and thus, mothers and women are the only ones playing a proactive role to protect the Lebanese traditional cuisine.

\title{
Like girls or even boys our age they don't even know how to cook Lebanese stews and they won't learn; with time, we won't be able to reproduce the Lebanese stews (Urban, boy).
}

Yet, education and work were particularly mentioned and foreseen by rural adolescent girls as a major barrier for cooking traditional Lebanese stew. Rural adolescent girls have mentioned that majority of their mothers are unemployed and mostly focus on the family interest which leaves them plenty of time to cook. 


\section{Theme 3: The Outer Environment}

Affordability was expressed as a very important factor in selecting a restaurant, a number of participants explained the choice of the Western type restaurant as being affordable for everyone. A suggestion of choosing fast foods over healthy choices when going out was from an economic perspective; stating that healthier choices are always more expensive than fast food. Some adolescents even mentioned that they would be spending money in restaurants on foods they cannot eat at home.

Girls living in the urban area seemed to be conforming to some social image and role modelling norms which were affecting their behaviors and in consequence the choice of the restaurant they visit. However, these social norms, were almost non-existent amongst rural girls focusing more on the proximity of the restaurant. Urban adolescent girls have showed an increased interest in their restaurant choice as a way maybe of expressing social status. As opposite to the urban area, snack bars in the rural area were small family-owned type of restaurants that however were selling Western type foods. In addition, it seemed that adolescent girls living in the rural area were least concerned with social norms and identities when selecting the choice of the restaurant as their main objective was to get some Western food available at proximity.

Fast foods snack bars at proximity of schools have created a real burden on healthy eating behaviors; many participants in both urban and rural area stated they head to a local snack bar neighboring the school to enjoy some Western food. On the other hand, some rural adolescents expressed an increased temptation and freedom in ditching home-made dishes when snack bars were near to their homes. Yet, some adolescents acknowledged their mothers as a barrier to having food from the snack bars at proximity of their home. It appeared that majority of adolescents recruited in the rural area were living at proximity of their school which increased their physical activity and their freedom in movement.

In the large urban area, majority of adolescents seemed to be living further from their school environment rather than within walking distance which in turn decreased their ability and freedom to walk after school-time especially in the absence of pedestrian safe roads and bicycle lanes.

A minority of adolescents in the urban area have justified their lack of physical activity due to the absence of public spaces in their local environment accentuating the lack of free basketball courts, public free gyms and many more;

I think the problem is the local municipalities, we don'thave public spaces like parks, free gyms, some football court. If you want to go to the gym you need to be driven there and pay a lot (Urban, boy).

\section{Theme 4: The School Environment}

The majority of participants agreed that the school environment was a barrier for healthy eating behaviors. Most agreed that the school's environment was not appropriate for food schemes. It appeared that adolescents did not trust the food sources nor the school system to be providing the best quality and the healthiest and freshest ingredients which was perceived as a barrier to eating fresh fruits at the school. Moreover, recess time was described by the majority of students as not enough to have a decent meal. Some participants even mentioned that having an imposed food scheme with a buffet style lunch would help them to adopt healthier behaviors. While majority of urban adolescents stressed about their cantina's food hygiene, it appeared that majority of adolescents in the rural area were satisfied with their food shop. 
Food choices are so limited, we've memorized all alternatives since we were 12 years old. Even the fattening food aren't diverse, you have to struggle to find something there is nothing if you're trying to get fit, nothing, except water obviously; a lot of choices are missing in the school food shops; there's a lot of chocolate butno yogurt for example, but it's very good they stopped selling Pepsi and crisps ... we need more professional staff, the same employee takes the money and makes our sandwiches (Urban, boy).

It was felt that adolescents had a contradictory opinion in regards to the food available in school, which is in line with the adolescence phase. Adolescents seemed to be wanting a healthier school environment while in the same time distressing on the low availability of junk snacks and foods. It seemed that majority of adolescents in the rural area were satisfied with their school food shop and were notvery critical about the food sold. Some adolescents also seemed to be emphasizing in a positive way on the availability of soft drinks.

The school environment appeared to be shaping some of the adolescents' food behaviors and preferences. In some of the focus groups in the urban area participants explained a change in their food preferences caused by the school food environment stating:

\section{Like Lebanese stews I got used to them since I was a kid, they are tasty, like when I was younger I used to like them way more with time when I started eating a bit outside of home like when I was younger I used to eat healthier and like when I started eating from the school's cantina things like hot-dog sandwiches and fattening sandwiches then like I'm not so used to eating the stews anymore so I started liking them a bit less (Urban, boy).}

The school environment was also perceived to affect their morning routine and eating behaviors indirectly; many of adolescents noted on the lack of time in the morning as a barrier to having breakfast. Participants explained that school time is too early.

\section{Theme 5: Social Influence}

Adolescence is a crucial period for role modelling and creating self-image, most of the adolescents mentioned specific trendy restaurants' names and food brands when asked about their lifestyle.

In the urban area, some other restaurants like for example 'McDonalds' were seen as tacky and were mentioned to mock their friends' practices. Some participants were using these types of restaurants as a way of sarcasm to mock their peers' behaviors. As well adolescents have showed some role modelling behaviors when surrounded with peers, in a sense that it was cooler not to have a healthy lifestyle. Adolescents' unhealthy food choices appeared to be a characteristic of adolescence, wanting to prove their rebellion and defiance for traditional and family-oriented choices.

A clear emphasis on the importance of peers as an influence on when, where and what kinds of foods they chose to eat was expressed by most adolescents. According to the majority of adolescents, peer influence and peer pressure were related to an unhealthy diet. Most of the adolescents felt surveilled and criticized when trying to adopt healthier food options when going out.

Some participants mentioned the difference between peers and friends. As peers were seen as closer people who know their flaws and motivations, friends on the other hand were 
people seen on special occasions and don't really know their lifestyle. Friends were even seen as a worsening factor to eating behaviors than peers.

\begin{abstract}
If I'm with someone that I'm really close to and who knows that like I'm trying to lose weight now I've started a diet and when I'm with someone close to me and knows what I'm going through and I need to get thinner, this person know, if, there is peer pressure there is a lot of peer pressure or if there's people who know that I'm trying to cut the extra weight I don't mind ordering grilled chicken or salad around them or a salad, but if I'm with someone who's a friend and it's been a long week than yea I order something fat (Urban, boy).
\end{abstract}

Adolescents also stated surveilling others in the recess time and relating their food behaviors in regard to their body appearance. Some eating behaviors were seen as a negative social image and role modelling. For example, adolescents who spent most of their times in the cantina were criticized and labelled as 'big body size'. Adolescents also labelled the students who brought Lebanese home-made cuisine with them to the school as being 'nerds'; this eating pattern was seen as a negative factor for adolescents.

It seemed that a majority of adolescents related being healthy to being fit and thus to the body image. The appearance of someone appeared to give insights on whether they are following healthy behaviors or not. Some participants and especially girls made a comment on the difference between genders; girls claimed that they were trying to have healthier behaviors when compared with boys. Some adolescents mentioned the difference of eating behaviors as well between genders.

Mostly, girls have mentioned the fact that boys are careless about their eating patterns and choices as opposite to them, as it will not affect in any way their body image nor their social status. The effect of eating patterns was related to body image in the majority of girls, as their priority was to look good in their prom dresses when graduating. Prom appeared to be a barrier to eating fast foods and an opportunity for healthy eating to girls specifically in the urban area. Girls, as opposed to boys, seemed to be pressured to assure a certain body image for society, and thus more prone to their parents' motivation and criticism.

To add-on, most of the adolescents stated that their mothers are continuously monitoring their foodbehaviors and always pushing them to eat traditional home-made Lebanese stews. Generally, most adolescents stated that their mother was in charge of preparing and providing food at home. In the opposite sense, adolescents perceived mothers as a key role in shaping eating behaviors since the early stages of childhood. Not only were mothers perceived as having a proactive role, but they were also blamed when their children had a preference towards Western food caused by their lack of skills in cooking properly Lebanese stews.

When asked what adolescents look for on social media, it appeared that there was a huge difference between the rural and urban areas especially in the way content was advertised. Many adolescents in both urban and rural area clarified that they don't 'follow' bloggers or influencers. It appeared that the growing impact of influencers on social media did not affect adolescents, clearly emphasizing that it is only for marketing purposes. On the other hand, it emerged that adolescents are mostly influenced by the opening of new restaurants in the urban area creating a certain trend and social norms. These restaurants seemed to be specifically targeting this age group as most of the urban adolescents stated seeing their promotion as sponsored adds on Instagram. 
Like now there is a new place that the famous TV host ... [name of TV personality] ... has opened and we feel like trying it because we saw so many pictures sponsored in our feed. So now we're excited to try it plus apparently, ... [name of TV personality] ... is always present in his restaurant (Urban, boy).

A clear emphasis on the importance of peers as an influence on when, where and what kinds of foods they chose to eat was expressed by most adolescents. According to the majority of adolescents, peer influence and peer pressure were related to an unhealthy diet. Most of the adolescents felt surveilled and criticized when trying to adopt healthier food options when going out.

\section{Discussion and Conclusion}

This study set out to investigate Lebanese adolescents' perceptions on factors influencing their eating behaviors in a nutrition transition phase. The findings provide insights on an area that has not been comprehensively explored and where the provision of more information from qualitative approaches, could be useful for research, recommendations and policies wishing to improve adolescents' eating behaviors, specially, in the Lebanese framework today.

In line with global trends, urbanization has been linked with the shift from traditional diets towards more processed and calorie rich foods (Popkin et al., 2012). The above findings indicate that both groups of urban and rural adolescents are consuming diets that are likely to be higher in fat, sugar, and salt than the traditional Lebanese diet. Adolescents in both urban and rural areas have showed an increased consumption in Western type foods especially when eating out with peers. This was particularly of interest in the rural area, as it appeared that Western type food was abundantly sold to adolescents through family-owned restaurants rather than international or local chain restaurants found in the urban area. This could suggest that the Westernization has also affected the rural area and thus is now affecting majority of Lebanon even outside of the urban cities. These findings are in line with the literature review such as in the UK and in the US (Casazza \& Ciccazzo, 2006; Story et al., 2002). Inconsistent with a previous study stating that majority of rural adolescents preferred traditional Lebanese dishes (Hamadeh, 2013), this study found that an increased preference towards available and affordable ultra-processed foods was especially noticed in the rural area, disregarding the availability of traditional Lebanese dishes in their household. This suggest the hypothesis that the consumption of ultra-processed foods is regarded as a sign of progress towards urbanization and symbol of higher economic status in LMICs rural areas (Steyn \& McHiza, 2014). The current findings are consistent with those of previous studies on the role of family members, and more precisely the role of mothers who are responsible for purchasing and preparing food, (Berhane et al., 2018), consequently preserving traditional dietary habits and influencing the availability of healthy foods in the household.

Key findings from this research highlight the importance of the social and environmental influences which are supported in the socio-ecological framework to understand better the adolescents' choices and eating behaviors (McLeroy et al., 1988). These findings highlight the importance of adolescence as a crucial period of role modelling and the creation of a social identity underpinning Bourdieu's 'habitus' theoretical framework (Bourdieu, 1989, 2005) as key factors in influencing and initiating a rebellion or change in the adolescents' food choices and behaviors. It also highlights the important relationship between the individual and their context such as on the interpersonal factor (mainly peers, friends, and parents) in shaping adolescents' eating behaviors. In this study, urban girls associated eating out with the creation of a social image for themselves, aligning with Bourdieu's 'habitus' theoretical framework. In contrast, boys in both areas associated eating out with snack bars and getting together with peers. The difference in attitude towards eating out could distinguish the food eaten in each case. Additionally, it appeared that adolescents' attitude about eating out was most of the time correlated with Western food and most precisely with unhealthy foods. The main barrier stated by adolescents' for 
choosing healthy foods when going out was related to taste preference, economical barriers, and peer pressure. To add-on, it also focuses on the importance of physical environment surrounding the adolescents in shaping their dietary behaviors which are included in Bronfenbrenner's Ecological Model (Bronfenbrenner, 1979).

Results from this study revealed that the factors which affect adolescents' food behaviors align well with the identified literature, such as food preferences and taste on the intrapersonal level (Di Noia \& Byrd-Bredbenner, 2013), peer pressure as an interpersonal factor (Salvy et al., 2012), availability of food in the community and organizational levels (Story et al., 2002) and media exposure in the macrosystem level which could be drawn as a sphere of influence (Banna et al., 2016; McLeroy et al., 1988).

The findings presented in this study showed that adolescents' eating behaviors in the urban and rural areas in Lebanon were both affected by the nutrition transition. They indicated that there has been a change in dietary behaviors in both areas including an increased consumption of ultra-processed foods and eating away from home, which suggests a shift away from traditional dietary practices consistent with the stages of nutrition transition. The drastic change in adolescents' dietary behaviors, was blamed on urbanization, as a major causation for obesity. This is in accordance with the literature whereby cheap ultra-processed foods are now widely available in rural areas of LMICs; therefore, reducing dietary behavior differences between areas (Popkin et al., 2020). Studies in Lebanon investigating the geographical disparities of obesity are still very scarce; only one study showed healthier dietary behaviors amongst adolescents in the rural area (Zeidan, 2007). It has long been thought that people residing in the rural area are physically more active, given the fact that they are more prone to working in farms and forestry, and healthier as they mainly consume local products from their own farms (Popkin et al., 2020). However, most of the policies and research stress tackling the drivers of obesity in the urban area while neglecting or denying its need in the rural area, although people living in the rural area are more exposed to the determinants of obesity (Popkin et al., 2020). This finding is fundamental since majority of obesity prevention programs around the world have been targeted to address urban obesity creating a major global gap related to rural obesity prevention (Popkin et al., 2020). Therefore, policy efforts and research should start by spreading knowledge and awareness amongst stakeholders and policymakers on the need to tackle the obesity problem in both urban and rural areas of Lebanon; given the fact that Lebanon is a small country, stakeholders expect minor differences between areas. To add-on, drafting multiple national policies that are rurally focused such as including fiscal and regulatory approaches, school-food controls and labels on ultra-processed foods and marketing controls is warranted to impact people's behavior (Popkin et al., 2020).

\section{Implications}

In line with the theoretical framework (Bronfenbrenner's model) used to underpin this research study, and with previous qualitative and quantitative studies, results from this study demonstrated the outstanding effect of both the physical and social environments on adolescents' eating behaviors and physical activity. However, this study noted that adolescents in the rural area are also undergoing the nutrition transition and are affected by similar determinants of obesity as those in the urban area, although previous research has indicated that the nutrition transition in Lebanon has only affected adolescents in the urban area. Regional differences have been noted in this study although the global determinants of obesity were the same. Capturing the voices of adolescents on the issues that affect them is crucial for developing effective, culturally relevant public health policies (Patton et al., 2016). Using adolescents' perceptions allows a system-level approach rather than an individual approach to the drivers of obesity in Lebanon representing both urban and rural environments. These results allow researchers to generate hypotheses on policy responses to obesity that are relevant to adolescents and their current environment. Subsequently, these interventions or policy responses are discussed with policy makers and key stakeholders using the system-level modelling. The combination of multiple interlinked strategies is required to embrace the complexity of the obesity problem targeting the multiple spheres of the environment surrounding adolescents such as the promotion of healthy eating inside and outside of 
school, school cantina policy, and the involvement of community policymakers. The development of a local network of key stakeholders is warranted in the development of a multilevel intervention for adolescents' obesity creating supportive environments for healthier lifestyle options. Ideally, stakeholders should include the local government, NGOs, the media, and the private sector (Summerbell et al., 2012). However, the need and adoption of a health promoting 'cities' approach or other relevant approach requires further public and political discussions and investigation especially in a LMIC undergoing several crises simultaneously.

\section{Limitations}

Every research has a number of limitations (Bloomberg \& Volpe, 2012). One potential limitation would be the purposive sampling technique used to recruit participants in both urban and rural areas. The focus of this study was to explore adolescents' perspectives and experiences of their eating behaviors within the nutrition transition. Although, the study findings were based on lengthy interviews, some parents' words may not have reflected their true views as they may have been influenced by social desirability. Finally, despite the bracketing of prior experiences that is integral to a qualitative study, it is noteworthy to consider the role of researcher bias and the influence of the assumptions the researcher brings to the interpretation of the qualitative results (Creswell, 2013; Creswell \& Poth, 2018). The identification of the main researcher as an alumnus of the urban school recruited could be a limiting factor; yet this did not affect the participants' choice in taking part in this study.

\section{Funding Details}

No financial incentives or grants were associated with this research project.

\section{Disclosure Statement}

There were no financial interests or benefits to any author or participant in this study.

\section{References}

Abdul Rahim, H., Sibai, A., Khader, Y., Hwalla, N., Fadhil, I., Alsiyabi, H., Mataria, A., Mendis, S., Mokdad, A. H., \& Husseini, A. (2014). Non-communicable diseases in the Arab world. Lancet, 383(9914), 356-367. https://doi.org/10.1016/S01406736(13)62383-1

Acocella, I. (2012). The focus groups in social research: Advantages and disadvantages. Quality \& Quantity, 46(4), 1125-1136. https://doi.org/10.1007/s11135-011-9600-4

Al-Badrashiny, M., Eskander, R., Habash, N., \& Rambow, O. (2014, June 26-27). Automatic transliteration of Romanized dialectal Arabic [Proceedings, pp. 30-38]. 18th Conference on Computational Natural Language Learning, Baltimore, United States.

Bagnoli, A., \& Clark, A. (2010). Focus groups with young people: A participatory approach to research planning. Journal of Youth Studies, 13, 101-109.

Bahn, R. A., \& Abebe, G. K. (2017). Analysis of food retail patterns in urban, peri-urban and rural settings: A case study from Lebanon. Applied Geography, 87, 28-44.

Banna, J. C., Buchthal O. V., Delormier T., Creed-Kanashiro H. M., \& Penny, M. E. (2016). Influences on eating: A qualitative study of adolescents in a periurban area in Lima, Peru. BMC Public Health, 16, 40.

Barbour, R. S., \& Kitzinger, J. (Eds.). (1999). Developing focus group research: Politics, theory and practice. Sage Publications. 
Berhane, H. Y., Ekström, E. C., Jirström, M., Berhane, Y., Turner, C., Alsanius, B. W., \& Trenholm, J. (2018). What Influences urban mothers' decisions on what to feed their children aged under five-The case of Addis Ababa, Ethiopia. Nutrients, 10(9), 1142.

Black, E. (2016). Globalisation of the food industry: Transnational food corporations, the spread of processed food, and their implications for food security and nutrition. Independent Study Project (ISP) Collection, 2353.

Bloomberg, L. D., \& Volpe, M. (2012). Completing your qualitative dissertation: A road map from beginning to end (2nd ed.). SAGE Publications.

Bouma, G. D., \& Atkinson, G. B. (1995). A handbook of social science research. Oxford University Press.

Bourdieu, P. (1986). The forms of capital. In J. G. Richardson (Ed.), Handbook of theory and research for the sociology of education (pp. 241-258). Greenwood Press.

Bourdieu, P. (1989). Distinction (R. Nice, Trans.). Routledge.

Bourdieu, P. (1998). Practical reason: On the theory of action. Stanford University Press.

Bourdieu, P. (2005). The social structures of the economy (C. Turner, Trans.). Polity Press.

Bourdieu, P. (2010). Distinction: A social critique of the judgement of taste. Taylor \& Francis.

Braun, V., \& Clarke, V. (2019). Reflecting on reflexive thematic analysis. Qualitative Research in Sport, Exercise \& Health, 11(4), 589-597.

Bronfenbrenner, U. (1979). The ecology of human development: Experiments by nature and design. Harvard University Press.

Bronfenbrenner, U. (1992). Ecology system theory. In R. Vasta (Ed.), Six theories of child development: Revised formulations and current issues (pp. 187-249). Jessica Kingsley Publishers.

Butland, B., \& Jebb, S. (2007). Foresight. Tackling obesities: Future choices. Project report. [online]. Available from: https://www.gov.uk/government/publications/reducingobesity-future-choices

Caranti, D. A., Lazzer, S., Dâmaso, A. R., Agosti, F., Zennaro, R., de Mello, M. T., Tufik, S., Sartorio, A. (2008). Prevalence and risk factors of metabolic syndrome in Brazilian and Italian obese adolescents: A comparison study. The International Journal of Clinical Pharmacy, 62, 1526-1532.

Casazza, K., \& Ciccazzo, M. (2006). Improving the dietary patterns of adolescents using a computer based approach. Journal of School Health, 76(2), 43.

Creswell, J. W. (2007). Qualitative inquiry \& research design. Choosing among five approaches (2nd ed.). SAGE Publications.

Creswell, J. W. (2013). Qualitative inquiry \& research design: Choosing among five approaches (3rd ed.). SAGE Publications.

Creswell, J. W. (2014). Research design qualitative, quantitative and mixed methods approaches (4th ed.). SAGE Publications.

Creswell, J. W., \& Poth, C. N. (2018). Qualitative inquiry and research design: Choosing among five approaches (4th ed.). SAGE Publications.

De Mattia, L., \& Denney, S. L. (2008). Childhood obesity prevention: Successful communitybased efforts. Annals of the American Academy of Political \& Social Science, 615, 8399.

De Vogli, R., Kouvonen, A., Elovainio, M., \& Marmot, M. (2014). Economic globalisation, inequality and body mass index: A cross-national analysis of 127 countries. Critical Public Health, 24(1), 7-21.

Demant, J., \& Järvinen, M. (2006). Constructing maturity through alcohol experience-Focus group interviews with teenagers. Addiction Research \& Theory, 14, 589-602.

Di Noia J., \& Byrd-Bredbenner C. (2013). Adolescent fruit and vegetable intake: Influence of family support and moderation by home availability of relationships with Afrocentric values and taste preferences. Journal Academic Nutrition \& Diet, 113(6), 803-808. 
Elderkin-Thompson, V., Silver, R. C., \& Waitzkin, H. (2001). When nurses double as interpreters: A study of Spanish-speaking patients in a US primary care setting. Social Science \& Medicine, 52(9), 1343-1358.

Fielden, A. L., Sillence, E., Little, L. (2011). Children's understandings' of obesity, a thematic analysis. International Journal of Qualitative Studies on Health \& Well-Being, 6.

Finegood, D. T., Merth, T. D., \& Rutter, H. (2010). Implications of the Foresight Obesity System Map for solutions to childhood obesity. Obesity, 18, S13-S16.

Fox, A., Feng, W., \& Asal, V. (2019). What is driving global obesity trends? Globalisation or "modernisation?" Globalization \& Health, 15, 32.

Fraser, L. K., Edwards, K. L., Cade, J. E., \& Clarke, G. P. (2011). Fast food, other food choices and body mass index in teenagers in the United Kingdom (ALSPAC): A structural equation modelling approach. International Journal of Obesity, 35(10), 1325-1330.

Gortmaker, S. L., Swinburn, B. A., Levy, D., Carter, R., Mabry, P. L., Finegood, D. T., Huang, T., Marsh, M., \& Moodie, M. L. (2011). Changing the future of obesity: Science, policy, and action. Lancet, 378(9793), 838-847.

Hamadeh, S. (2013). Perceptions par divers acteurs d'une politique éventuelle de promotion de santé nutritionnelle en milieu scolaire libanais. Universite de Montreal.

Hills, A. P., Andersen, L. B., \& Byrne, N. M. (2011). Physical activity and obesity in children. British Journal of Sports Medicine, 45(11), 866-870.

Holsten, J. E. (2009). Obesity and the community food environment: A systematic review. Public Health Nutrition, 12, 397-405.

Kamphuis, C. B., Jansen, T., Mackenbach, J. P., \& Lenthe, F. J. (2015). Bourdieu's cultural capital in relation to food choices: A systematic review of cultural capital indicators and an empirical proof of concept. Plos One, 10(8).

Kleinert, S., \& Horton, R. (2015). Rethinking and reframing obesity. The Lancet, 385, 23262328.

Krueger, R. A., \& Casey, M. A. (2009). Focus groups: A practical guide for applied research (4th ed.). Sage Publications.

Lange, D., Wahrendorf, M., Siegrist, J., Plachta-Danielzik, S., Landsberg, B., \& Müller, M. J. (2011). Associations between neighbourhood characteristics, body mass index and health-related behaviours of adolescents in the Kiel Obesity Prevention Study: A multilevel analysis. European Journal of Clinical Nutrition, 65(6), 711-719.

Lee, K., Koivusalo, M., Ollila, E., Labonté, R., Schrecker, T., Schuftan, C., \& Woodward, D. (2007). WHO commission on social determinants of health. Globalization, global governance and the social determinants of health. A review of the linkages and agenda for action. Institute of population health. uOttowa.

Lincoln, Y. S., \& Guba, E. G. (1985). Naturalistic inquiry. Sage Publications.

Lobstein, T., Jackson-Leach, R., Moodie, M. L., Hall, K. D., Gortmaker, S. L., Swinburn, B. A., James, W. P. T., Wang, Y., \& Mcpherson, K. (2015). Child and adolescent obesity: Part of a bigger picture. The Lancet, 385(9986), 2510-2520.

Lopez, A. M., Loopstra, R., McKee, M., \& Stuckler, D. (2017). Is trade liberalisation a vector for the spread of sugar-sweetened beverages? A cross-national longitudinal analysis of 44 low- and middle-income. Social Science \& Medicine, 172, 21-27.

Mackenbach, J. D., Rutter, H., Compernolle, S., Glonti, K., Oppert, J., Charreire, H., De Bourdeaudhuij, I., Brug, J., Nijpels, G., \& Lakerveld, J. (2014). Obesogenic environments: A systematic review of the association between the physical environment and adult weight status, the SPOTLIGHT project. BMC Public Health, 14(1).

McLeroy, K. R., Bibeau, D., Steckler, A., \& Glanz, K. (1988). Ecological perspective on promotion programs. Health Education Quarterly, 15(4), 351-377. 
Moffat, C., Dorris, L., Connor, L., Espie, C. A. (2009). The impact of childhood epilepsy on quality of life: A qualitative investigation using focus group methods to obtain children's perspectives on living with epilepsy. Epilepsy \& Behavior, 14, 179-189.

Molina, L., \& Albir, A. H. (2004). Translation techniques revisited: A dynamic and functionalist approach. Meta: Translators' Journal, 47(4), 498-512.

Montaño, Z., Smith, J. D., Dishion, T. J., Shaw, D. S., \& Wilson, M. N. (2015). Longitudinal relations between observed parenting behaviors and dietary quality of meals from ages 2 to 5. Appetite, 87, 324-329.

Morgan, M., Gibbs, S., Maxwell, C., \& Britten, N. (2002). Hearing children's voices: Methodological issues in conducting focus groups with children aged 7-11 years. Qualitative Research, 2, 5-20.

Murray, R., \& Battista, M. (2009). Managing the risk of childhood overweight and obesity in primary care practice. Current Problems in Pediatric \& Adolescent Health Care, 39(6), $146-165$.

Musaiger, A. O. (2011). Overweight and obesity in Eastern Mediterranean region: Prevalence and possible causes. Journal of Obesity, 2011, 1-17.

Naja, F., Shatila, H., Meho, L., Alameddine, M., Haber, S., Nasreddine, L., Sibai, A. M., \& Hwalla, N. (2017). Gaps and opportunities for nutrition research in relation to noncommunicable diseases in Arab countries: Call for an informed research agenda. Nutrition Research, 47, 1-12.

Nasreddine, L., Hwalla, N., Saliba, A., Akl, C., \& Naja, F. (2017). Prevalence and correlates of preschool overweight and obesity amidst the nutrition transition: Findings from a national cross-sectional study in Lebanon. Nutrients, 9(3), 266.

Nasreddine, L., Naja, F., Akl, C., Chamieh, M., Karam, S., Sibai, A., \& Hwalla, N. (2014). Dietary, lifestyle and socio-economic correlates of overweight, obesity and central adiposity in Lebanese children and adolescents. Nutrients, 6(3), 1038-1062.

Nasreddine, L., Naja, F., Tabet, M., Habbal, M. Z., El-Aily, A., Haikal, C., Sidani, S., Adra, N., \& Hwalla, N. (2012). Obesity is associated with insulin resistance and components of the metabolic syndrome in Lebanese adolescents. Annals of Human Biology, 39, 122128.

O'Connell, R. (2010). (How) is childminding family like? Family day care, food and the reproduction of identity at the public/private interface. The Sociological Review, 58(4), 563-586.

Oberlander, L., Disdier, A. C., \& Etilé, F. (2017). Globalisation and national trends in nutrition and health: A grouped fixed-effects approach to intercountry heterogeneity. Journal of Health Economics, 26, 1146-1161.

Oliver, S., \& Peersman, G. (2001). Using research for effective health promotion. Open University Press.

Omran, A. (1971). The epidemiologic transition: A theory of the epidemiology of population change. The Milbank Memorial Fund Quarterly Health \& Society, 49, 509-538.

Oncini, F., \& Guetto, R. (2017). Determinants of dietary compliance among Italian children: Disentangling the effect of social origins using Bourdieus cultural capital theory. Sociology of Health \& Illness, 39(1), 47-62.

Oxley, J., Günhan, E., Kaniamattam, M., \& Damico, J. (2017). Multilingual issues in qualitative research. Clinical Linguistics \& Phonetics, 31(7-9), 612-630.

Pampel, F. C. (2011). Does reading keep you thin? Leisure activities, cultural tastes, and body weight in comparative perspective. Sociology of Health \& Illness, 34(3), 396-411.

Pampel, F. C., Krueger, P. M., \& Denney, J. T. (2010). Socioeconomic disparities in health behaviors. Annual Review of Sociology, 36(1), 349-370. 
Panter, J., Andersen, P. T., Aro, A. R., \& Samara, A. (2018). Obesity prevention: A systematic review of setting-based interventions from Nordic countries and the Netherlands. Journal of Obesity, 2018, 1- 34.

Patton, G. C., Sawyer, S. M., Santelli, J. S., Ross, D. A., Afifi, R., Allen, N. B., Arora, M., Azzopardi, P., Baldwin, W., Bonell, C., Kakuma, R., Kennedy, E., Mahon, J., McGovern, T., Mokdad, A. H., Patel, V., Petroni, S., Reavley, N., Taiwo, K., . . Viner, R. M. (2016). Our future: A Lancet commission on adolescent health and wellbeing. Lancet, 387(10036), 2423-2478.

Pinxten, W., \& Lievens, J. (2014). The importance of economic, social and cultural capital in understanding health inequalities: Using a Bourdieu-based approach in research on physical and mental health perceptions. Sociology of Health \& Illness, 36(7), 10951110.

Popkin, B. M. (2015). Nutrition transition and the global diabetes epidemic. Current Diabetes Reports, 15(9), 64.

Popkin, B. M., Adair, L. S., \& Ng, S. W. (2012). Global nutrition transition and the pandemic of obesity in developing countries. Nutrition Reviews, 70(1), 3-21.

Popkin, B. M., Corvalan, C., \& Grummer-Strawn, L. M. (2020). Dynamics of the double burden of malnutrition and the changing nutrition reality. Lancet, 395(10217), 65-74.

Rockefeller Foundation. (2013). Unhealthy Developing World Food Markets. Rockefeller Foundation.

Roth, J., Qiang, X., Marbán, S. L., Redelt, H., \& Lowell, B. C. (2012). The obesity pandemic: Where have we been and where are we going? Obesity Research, 12, 88S-101S.

Salas, X. R. (2015). The ineffectiveness and unintended consequences of the public health war on obesity. Canadian Public Health Association, 106(2), e79-e81.

Salvy, S. J., de la Haye, K., Bowker, J. C., \& Hermans, R. C. (2012). Influence of peers and friends on children's and adolescents' eating and activity behaviors. Physiology \& behavior, 106(3), 369-378.

Siegel, K. R. (2019). Insufficient consumption of fruits and vegetables among individuals 15 years and older in 28 low- and middle-income countries: What can be done? The Journal of Nutrition, 149(7), 1105-1106.

Simons-Morton, D. G., Simons-Morton, B. G., Parcel, G. S., \& Bunker, J. F. (1988). Influencing personal and environmental for community health: A multilevel intervention model. Family \& Community health, 11(2), 25-35.

Spear, B. A. (2002). Adolescent growth and development. The American Dietetic Journal, 102(3), S23-S29.

Stewart, H., Blisard, N., \& Joliffe, D. (2006). Let's eat out: American weight taste, convenience and nutrition. Economic Bulletin, 19. USDA/ERS.

Steyn, N. P., \& Mchiza, Z. J. (2014). Obesity and the nutrition transition in Sub-Saharan Africa: Obesity and the nutrition transition. Annals of the New York Academy of Sciences, 1311, 88-101.

Story, M., Neumark-Sztainer, D., \& French, S. (2002). Individual and environmental influences on adolescent eating behavior. Journal of the American Dietetic Association, 102(3), S40-S52.

Summerbell, C. D., Moore, H. J., Vögele, C., Kreichauf, S., Wildgruber, A., Manios, Y., Douthwaite, W., Nixon, C. A., \& Gibson, E. L. (2012). Evidence-based recommendations for the development of obesity prevention programs targeted at preschool children. Obesity Reviews, 13, 129-132.

Swinburn, B. A., Egger, G., \& Raza, F. (1999). Dissecting obesogenic environments: The development and application of a framework for identifying and prioritizing environmental interventions for obesity. Preventive Medicine, 29(6), 563-570. 
Swinburn, B. A., Kraak, V. I., Allender, S., Atkins, V. J., Baker, P. I., Bogard, J. R., Brinsden, H., Calvillo, A., De Schutter, O., Devarajan, R., Ezzati, M., Friel, S., Goenka, S., Hammond, R. A., Hastings, G., Hawkes, C., Herrero, M., Hovmand, P. S., Howden, M., . . \& \& Dietz, W. H. (2019). The Global syndemic of obesity, undernutrition, and climate change: The Lancet Commission report. Lancet, 18, 32822-32828.

Swinburn, B. A., Sacks, G., Hall, K. D., McPherson, K., Finegood, D. T., Moodie, M. L., \& Gortmaker, S. L. (2011). The global obesity pandemic: Shaped by global drivers and local environments. The Lancet, 378(9793), 804-814.

Tull, K. (2018). Urban food systems and nutrition. K4D Helpdesk Report 383. Institute of Development Studies.

Ulijaszek, S. (2015). With the benefit of foresight: Obesity, complexity and joined-up government. BioSocieties, 10(2), 213-228.

United Nations Population Division. (2019). World population prospects. United Nations. DESA.

Wang, Y., Jia, P., Cheng, X., \& Xue, H. (2019). Improvement in food environments may help prevent childhood obesity: Evidence from a 9-year cohort study. Pediatric obesity, 14(10), e12536.

Warren, C. A. B. (2002). Qualitative interviewing. In J. F. Gubrium \& J. A. Holstein (Eds.), Handbook of interview research: Context and method. Sage.

Weihrauch-Blüher, S., Kromeyer-Hauschild, K., Graf, C., Widhalm, K., Korsten-Reck, U., Jödicke, B., Markert, J., Müller, M. J., Moss, A., Wabitsch, M., \& Wiegand, S. (2018). Current guidelines for obesity prevention in childhood and adolescence. Obesity Facts, 11(3), 263-276.

World Health Organization (2016a). Non-communicable diseases. https://www.who.int/gho/ncd/mortality_morbidity/en/

World Health Organization (2016b). Report of the Commission on Ending Childhood Obesity. http://apps.who.int/iris/bitstream/10665/204176/1/9789241510066_eng.pdf?ua=1\&ua $=1$

World Health Organization (2017). The double burden of malnutrition: policy brief. http://www.who.int/nutrition/publications/doubleburdenmalnutrition- policybrief/en/

World Health Organization (2018). Monitoring food marketing to children in Turkey. WHO.

World Health Organization. (1986). The Ottawa Charter for Health Promotion. WHO Regional Office for Europe.

World Health Organization. (2000). Obesity: Preventing and managing the global epidemic: Report of a WHO consultation. http://whqlibdoc.who.int/trs/who_trs_894.pdf

Zeidan, M. N. (2007). The development, implementation and evaluation of a multi-component nutrition education intervention to promote healthy eating among two Lebanese adolescent samples from contrasting socioeconomic status [Unpublished $\mathrm{PhD}$ thesis]. University of Leicester. 


\section{Notes on Contributors}

Dr. Miriam Bou Kheir completed her $\mathrm{PhD}$ in public health nutrition at the University of Chester, UK. Her PhD research and the general aim of her research is to explore the effect of the nutrition transition on adolescents' eating behavior in LMICs and more particularly Lebanon. Prior to her PhD studies, Miriam completed her MSc. in Human Nutrition at the University of Chester. She is as well a Licensed Dietitian in Lebanon and holds a bachelor degree in Nutrition and Dietetics from the Holy Spirit University of Kaslik (USEK), Lebanon.

Professor Stephen Fallows completed his BSc in Nutrition from the University of London. Immediately after graduating Prof Fallows worked in the Eastern Province of Zambia for a local organization, Dzithandizeni Chipata Nutrition Group, concerned with nutrition education and other actions to promote nutritional wellbeing of the local people. The work was supported by OXFAM, NOVIB and other organizations. On his return to the UK he completed a PhD in food and nutrition policy at the University of Bradford. Since 2001, Prof Fallows has been with the University of Chester in a variety of teaching and research roles. E-mail: s.fallows@chester.ac.uk

Professor Lynne Kennedy completed a $\mathrm{PhD}$ in public health nutrition at the University of Liverpool, UK. With over 30 years' experience as an academic in Public Health Nutrition, working in Higher Education, and including over 10 years' experience in strategic and senior academic leadership positions including Head of Subject and Associate Dean; she is currently based at Zayed University, UAE. E-mail: Lynne.Kennedy@zu.ac.ae

Manuscript received April 30, 2021

Final revision received May 22, 2021

Accepted May 24, 2021 